\title{
Efeito das Condições de Preparação na Condutividade Elétrica de Blendas de Poli(fluoreto de vinilideno) e Poli(o-metoxianilina).
}

\author{
Luiz Francisco Malmonge e Luiz Henrique C. Mattoso.
}

Resumo: Neste trabalho estudou-se o efeito das condições de preparação na condutividade elétrica de blendas condutoras de poli(fluoreto de vinilideno) (PVDF) com poli(o-metoxianilina) (POMA). A condutividade elétrica e a qualidade dos filmes produzidos dependem significativamente do solvente, dopante e das condições de preparação das blendas. Filmes flexíveis e auto-sustentáveis da blenda PVDF/POMA dopada com o ácido p-tolueno sulfônico (TSA) foram obtidos em condições otimizadas. Estes apresentam condutividade elétrica em uma larga faixa $\left(10^{-12}-10^{-2} \mathrm{~S} / \mathrm{cm}\right)$, onde para baixos teores de POMA-TSA $(<2,0 \%$ em massa $)$ já se atinge alto valor de condutividade $\left(10^{-7} \mathrm{~S} / \mathrm{cm}\right)$, não sendo definida uma composição mínima para percolação.

Palavras-chave: Polímeros condutores, blendas, poli(fluoreto de vinilideno), polianilina, derivados.

\section{Introdução}

Polímeros condutores têm despertado um grande interesse científico e tecnológico nos últimos anos, devido às suas interessantes propriedades, em particular, sua alta condutividade elétrica ${ }^{[1]}$. As polianilinas estão exercendo um papel importante neste campo devido à sua facilidade de dopagem com ácidos protônicos e sua estabilidade química no estado dopado ${ }^{[2]}$.

A processabilidade de polímeros condutores é um fator crucial no uso de suas propriedades elétricas e eletroquímicas em aplicações tecnológicas. Um marco a este respeito foi a descoberta de que se podem obter filmes ${ }^{[3]}$ e fibras ${ }^{[4]}$ de polianilinas a partir de suas soluções. Outro progresso importante tem sido o desenvolvimento de métodos para a preparação de blendas de polianilinas com um grande número de polímeros convencionais ${ }^{[5-10]}$ dentre os quais se destacam: copolímero tribloco de estireno-etileno/ butileno-estireno $^{[8]}$, poliestireno ${ }^{[9]}$, Náilon $6-6^{[9]} \mathrm{e}$ poli(metacrilato de metila) ${ }^{[10]}$. Estes avanços têm aumentado consideravelmente o potencial tecnológico e a viabilidade comercial dos polímeros condutores. Essas blendas possibilitam a obtenção de materiais poliméricos com condutividade em larga faixa $^{[10]}$ e com propriedades mecânicas melhores quando comparadas às do polímero condutor.

Embora seja reconhecido que as propriedades destes materiais poliméricos, em geral, são altamente afetadas pelo método e condições utilizadas na sua

Luiz Francisco Malmonge, Depto. de Física e Química - UNESP, Ilha Solteira, 15385-000, São Paulo, Brasil. e Instituto de Química de São Carlos-USP, São Carlos, 13560-970, São Paulo, Luiz Henrique C. Mattoso, Centro Nacional de Pesquisa e Desenvolvimento de Instrumentação Agropecuária CNPDIAI EMBRAPA, CP 741, São Carlos, 13560-970, São Paulo. 
preparação, pouco ainda tem sido investigado para se elucidar este efeito ${ }^{[5-10]}$. Neste contexto, este trabalho se propõe a estudar o efeito das condições de preparação e dopagem de blendas de poli(o-metoxianilina) (POMA) e poli(fluoreto de vinilideno) (PVDF) na condutividade elétrica e na qualidade (flexibilidade e homogeneidade) de filmes obtidos por solução.

\section{Experimental}

\section{Síntese do Polímero Condutor}

A POMA foi sintetizada quimicamente usando persulfato de amônio em meio ácido aquoso de $\mathrm{HCl}$ $1,0 \mathrm{M}$ a $0^{\circ} \mathrm{C}$ como descrito na literatura ${ }^{[11]}$. A razão molar de monômero por oxidante foi de $4: 1$. A desdopagem foi feita usando hidróxido de amônio $0,1 \mathrm{M}$, por 16 horas a temperatura ambiente, para produzir o polímero na forma base esmeraldina (EB). A dopagem protônica foi realizada dissolvendo-se primeiramente o polímero desdopado e então dopandoo pela adição de ácido concentrado na solução. Foram usados os ácidos p-toluenosulfônico (TSA), trifluoracético (TFA) e metileno sulfônico (MSA).

\section{Preparação das blendas}

O PVDF, Foraflon $4000 \mathrm{HD}$, foi obtido da Atochem e usado como recebido. As soluções da POMA (2g/dL) e de PVDF $(10 \mathrm{~g} / \mathrm{dL})$ foram preparadas separadamente à temperatura ambiente e a $70^{\circ} \mathrm{C}$, respectivamente. A preparação das blendas de PVDF/POMA foi realizada pela mistura das soluções desses polímeros em diferentes composições. Os filmes $(15-30 \mu \mathrm{m}$ de espessura) foram obtidos pelo método do derrame (casting) em lâminas de vidros em uma estufa de $50^{\circ} \mathrm{C}$ a $150^{\circ} \mathrm{C}$ (conforme especificado) com circulação de ar. O tempo de evaporação do solvente variou de 1 a 24 horas dependendo do solvente usado. Filmes das blendas de PVDF/POMA foram obtidos utilizando-se os solventes $\mathrm{N}, \mathrm{N}$-dimetilformamida (DMF), N,N-dimetilacetamida (DMA) e N-metilpirrolidona (NMP) e dopando-os com os ácidos, TSA, TFA e MSA.

\section{Caracterização}

Espectros de absorção de UV-Vis-NIR, dos polímeros tanto em solução de DMA como na forma de filmes, foram obtidos usando um Espectofotômetro de feixe duplo da marca Varian Cary modelo 2315. A condutividade elétrica $(\sigma)$ foi medida pelo método de quatro pontas. Os difratogramas de raios-X foram obtidos em um difratômetro Rigaku-Rotoflex modelo RV-200B, usando radiação em $\mathrm{K} \alpha \mathrm{Cu}$ de comprimento de onda igual a $1,54 \AA$. As micrografias foram obtidas em um microscópio eletrônico de varredura (MEV) computadorizado Zeiss DSM 960, utilizando-se um feixe de elétrons de $20 \mathrm{kV}$. Para isto, as amostras foram preparadas colando-se os filmes com tinta de prata para se obter um bom contato elétrico. Sobre este filme foi depositado uma fina camada de ouro (15nm), usando um Sputter Coater (plasma de argônio) da Balzers modelo SCD 50.

\section{Resultados e Discussão}

Na preparação das blendas de PVDF/POMA verificou-se que a combinação dopante/solvente influencia diretamente as propriedades físicas dos filmes. Desta forma um estudo da preparação das blendas e obtenção dos filmes, utilizando os solventes DMF, DMA e NMP e os dopantes TSA, TFA e MSA, foi realizado. Na Tabela 1 são encontrados os valores da condutividade elétrica obtidos para filmes da blenda de PVDF/POMA (75/25) com diferentes combinações dopante/solvente. Os filmes obtidos para as blendas preparadas com DMF e DMA dopados com TSA apresentaram os maiores valores de condutividade elétrica. Os filmes preparados em DMA e dopados com TSA foram visivelmente mais homogêneos (coloração uniforme) e flexíveis, sendo portanto utilizados nos estudos subsequentes. O NMP produziu filmes com valores menores de condutividade que os demais, devido a maior basicidade deste solvente. Este fato pôde ser notado pela coloração da solução NMP/POMA-TSA, que se mostrou azulada (característica da forma desdopada) para altas diluições de POMA-TSA ${ }^{[12,16]}$.

Tabela 1. Condutividade elétrica $(\sigma)$ de filmes da blenda PVDF/POMA (75/25) preparados com diferentes combinações de solvente e dopante.

$$
\sigma(\mathrm{S} / \mathrm{cm})
$$

\begin{tabular}{cccc} 
& TFA & TSA & MSA \\
\hline DMF & $1,6 \times 10^{-3}$ & $3,0 \times 10^{-3}$ & $1,0 \times 10^{-5}$ \\
DMA & $2,6 \times 10^{-4}$ & $2,4 \times 10^{-3}$ & $1,8 \times 10^{-4}$ \\
NMP & $<10^{-7}$ & $3,0 \times 10^{-5}$ & $6,0 \times 10^{-5}$ \\
\hline
\end{tabular}




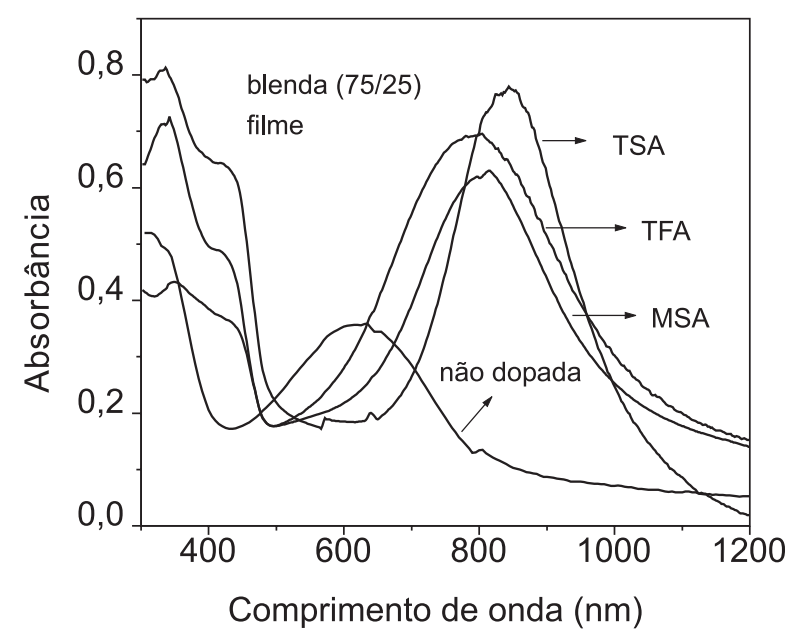

Figura 1. Espectros de UV-Vis-NIR de filmes da blenda de PVDF/POMA (75/25), preparados em DMA e dopados com diferentes dopantes, conforme indicado.

A Figura 1 ilustra os espectros de UV-Vis-NIR da blenda de PVDF/POMA (75/25) na forma de filme. Nota-se que o espectro da blenda não dopada apresenta duas bandas de absorção. A primeira em torno de $320 \mathrm{~nm}(3,88 \mathrm{eV})$ é atribuída à transição $\pi-\pi^{*}$ devido aos anéis benzênicos da cadeia polimérica ${ }^{[12]}$. A segunda banda em torno de $620 \mathrm{~nm}(2,00 \mathrm{eV})$ é atribuída à transição do exciton molecular que está relacionada com a transferência de cargas dos anéis benzenóides para o anel quinóide ${ }^{[12]}$. Para as blendas dopadas, observam-se três bandas de absorção. A primeira aparece um pouco deslocada em relação ao polímero não dopado em torno de $340 \mathrm{~nm}(3,65 \mathrm{eV})$. A segunda em torno de $440 \mathrm{~nm}(2,82 \mathrm{eV})$ e a terceira, em torno de $810 \mathrm{~nm}(1,53 \mathrm{eV})$ para os filmes dopados com TFA e MSA, e em $840 \mathrm{~nm}(1,47 \mathrm{eV})$ para o filme dopado com TSA, que correspondem à formação de pólarons na cadeia polimérica ${ }^{[12]}$. Estas duas últimas bandas estão relacionadas com a condutividade devido ao processo de dopagem, indicando que para o TSA obtém-se um filme com menor energia para a transição eletrônica, consistente com o maior valor de condutividade obtido quando comparado com os demais dopantes. Além disso, esses espectros são basicamente idênticos aos obtidos por solução, indicando que durante o processo de preparação destes filmes não deve haver perda de dopante.

Os espectros de UV-Vis-NIR da blenda de PVDF/ POMA é mostrado na Figura 2 para diferentes conteúdos de POMA dopada com TSA. Observa-se que as posições das bandas de absorção não variam com a quantidade de polímero condutor, mostrando que mesmo para uma pequena quantidade de POMA a

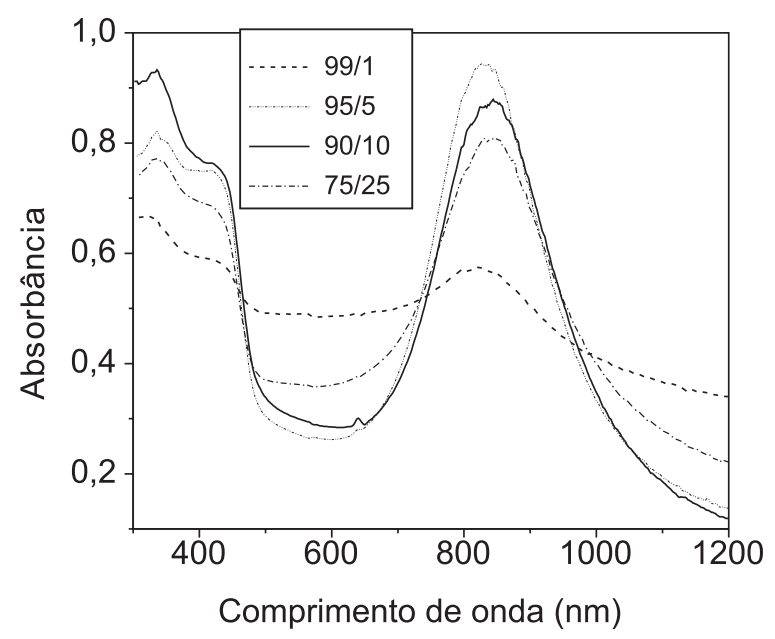

Figura 2. Espectros de UV-Vis-NIR de filmes das blendas, preparadas em DMA, com diferentes composições de PVDF/POMA (conforme indicado), dopados com TSA.

blenda permanece dopada, não sofrendo desdopagem pela diluição da POMA na matriz isolante.

$\mathrm{O}$ efeito da temperatura de evaporação $\left(\mathrm{T}_{\mathrm{E}}\right)$ do solvente na condutividade elétrica da blenda de PVDF/ POMA (75/25) dopada com TSA pode ser visto na Figura 3. A temperatura de evaporação influi decisivamente na condutividade da blenda (Figura 3a). O valor da condutividade do filme obtido a $150^{\circ} \mathrm{C}$ $\left(3,6 \times 10^{-4} \mathrm{~S} / \mathrm{cm}\right)$ é aproximadamente uma ordem de grandeza menor do que aquele obtido a $50^{\circ} \mathrm{C}$ $\left(3,5 \times 10^{-3} \mathrm{~S} / \mathrm{cm}\right)$. Um dos fatores que contribui para esta variação são as diferentes morfologias obtidas nas temperaturas estudadas, conforme será demonstrado posteriormente por MEV. Além disso, perdas do ácido dopante e/ou solvente residual, também podem contribuir para este comportamento. O filme obtido a $50^{\circ} \mathrm{C}$ mostrou ser mais condutor e mais homogêneo que os demais, o que não ocorreu com os filmes obtidos em temperaturas inferiores a $50^{\circ} \mathrm{C}$. A curva (b) da Figura 3 mostra que o valor da condutividade elétrica é pouco influenciado pelo tempo de evaporação do solvente para o filme obtido a $50^{\circ} \mathrm{C}$.

O conteúdo de dopante presente na blenda influencia diretamente a condutividade dos filmes (Figura 4). Isto foi verificado para blendas de PVDF/POMA $(75 / 25)$ obtidas a $50^{\circ} \mathrm{C}$, dopadas em solução, sendo que a quantidade de dopante é calculada em relação ao número de moles de um tetrâmero da POMA. Notase que a condutividade aumenta significativamente, tendendo a um patamar a partir de $50 \%$ de dopagem em massa, ou seja, 50\% dos nitrogênios iminas se encontram protonados pelo dopante. Para conteúdos de dopante acima de $50 \%$ as propriedades físicas e 


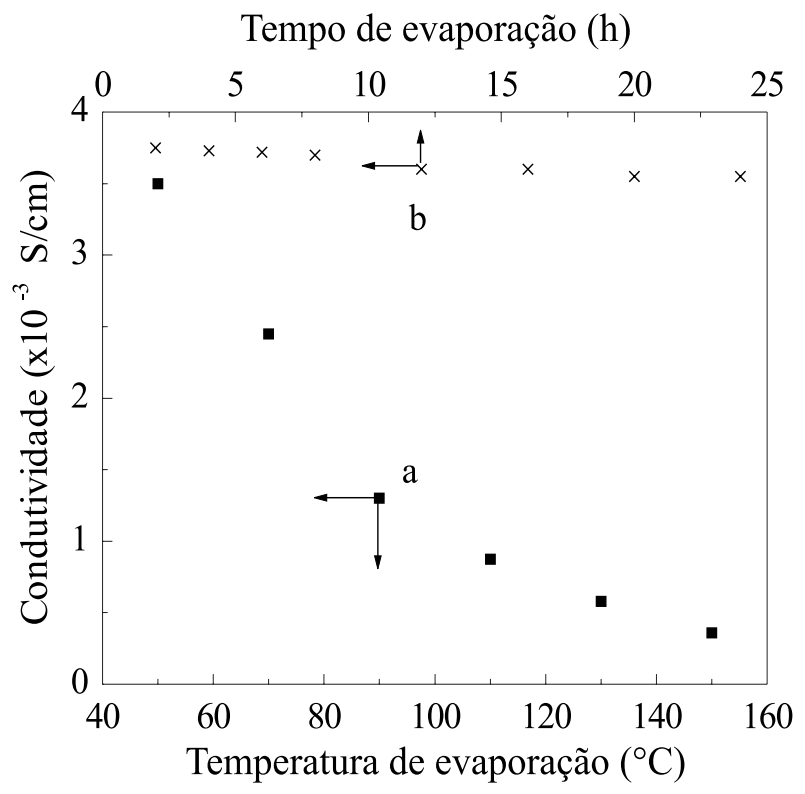

Figura 3 - Condutividade elétrica da blenda de PVDF/POMA (75/25) dopada com TSA em função das condições de preparação dos filmes: (a) temperatura de evaporação do solvente (DMA); (b) tempo de evaporação do solvente para o filme obtido a $50^{\circ} \mathrm{C}$.

mecânicas dos filmes começam a ser afetadas, tornando-os quebradiços e não homogêneos.

Esse comportamento pode ser explicado considerando que o estado de oxidação mais estável das polianilinas, no caso a POMA, é o estado de oxidação esmeraldina, no qual o polímero está $50 \%$ oxidado $^{[11]}$. Neste caso atingem-se os maiores valores de condutividade após dopagem. Desta forma, acreditase que o máximo de dopagem para a POMA na blenda também seja $50 \%$ de protonação, referente à dopagem de dois nitrogênios imina dos quatro nitrogênios totais do tetrâmero de POMA. Acima desta quantidade o

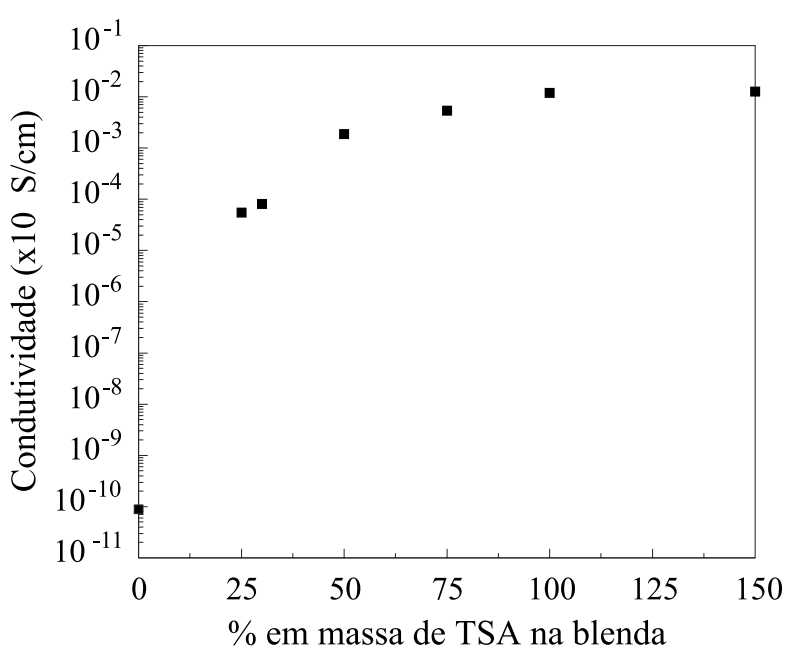

Figura 4 - Condutividade elétrica em função da quantidade de dopante (TSA) adicionado à blenda de PVDF/POMA (75/25). (Solvente: DMA, $\left.\mathrm{T}_{\mathrm{E}}: 50^{\circ} \mathrm{C}\right)$.

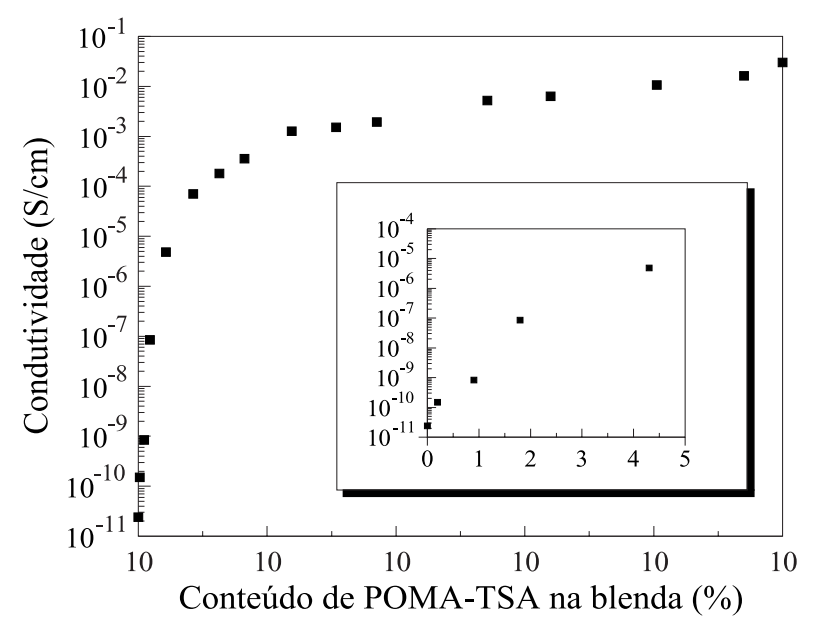

Figura 5 - Condutividade elétrica em função do conteúdo de POMATSA na blenda com PVDF (DMA, $\mathrm{T}_{\mathrm{E}}=50^{\circ} \mathrm{C}$ ). $\mathrm{O}$ quadro em destaque mostra o valor da condutividade para as composições menores que 4,5\%, em massa, de POMA -TSA na blenda.

dopante fica em excesso no material, o que provoca prejuízo na flexibilidade do filme obtido.

O comportamento da condutividade elétrica de filmes das blendas de PVDF/POMA-TSA é ilustrado na Figura 5 para diferentes composições PVDF/ POMA. É importante ressaltar que a melhor combinação de desempenhos em condutividade elétrica e flexibilidade foi obtida para a blenda contendo $25 \%$ de POMA. Para composições acima de $40 \%$ de polímero condutor na blenda, foi utilizada a POMA de alta massa molar*, devido à baixíssima resistência mecânica e flexibilidade da POMA de baixa massa molar, o que não permitia obter filmes auto-sustentáveis, que pudessem ser manuseados. Deve-se salientar também, que testes feitos com a blenda (75/25) utilizando POMA de alta e baixa massa molar, apresentaram filmes com valores de condutividade na mesma ordem de grandeza.

Como pode ser observado na Figura 5, a condutividade aumenta significativamente com o conteúdo de POMA na blenda, desde baixos teores de POMA-TSA na blenda ( $<2,0 \%$ em massa), não sendo definida uma composição mínima para percolação. Este aumento é ainda mais significativo para baixas composições para o qual a condutividade aumenta seis ordens de grandeza, de $10^{-11}$ para $10^{-5} \mathrm{~S} / \mathrm{cm}$, respectivamente, para o PVDF e para a blenda com 4,5\%,

\footnotetext{
*A POMA de alta massa molar foi obtida por síntese química com duas alterações em relação a de baixa massa molar, a saber: adição do sal $\mathrm{LiCl}(0,752 \mathrm{~mol})$ na solução de $\mathrm{HCl} 1,0 \mathrm{M}$ e o tempo de polimerização, passando de 4 para 8 horas $\left(\overline{\mathrm{M}}_{\mathrm{w}}=111.600 \mathrm{~g} / \mathrm{mol}^{[11,16]}\right)$
} 


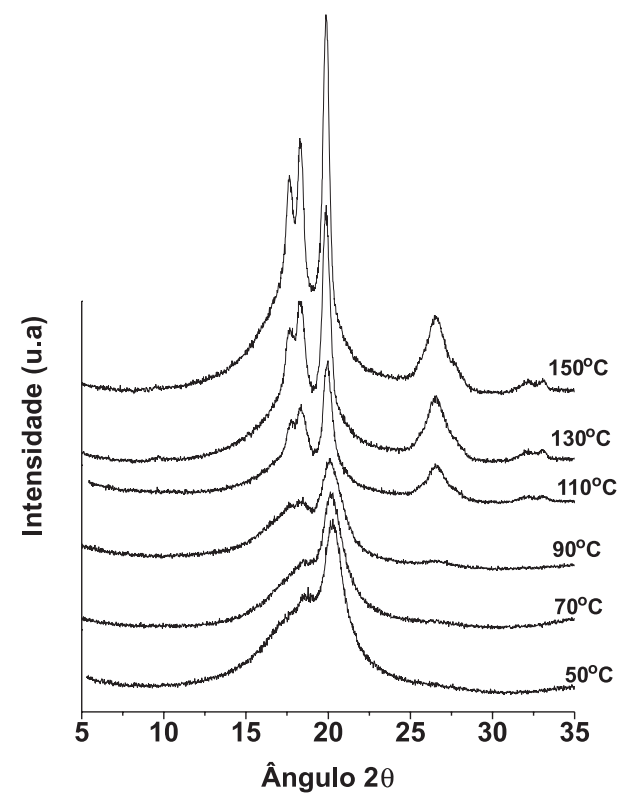

Figura 6 - Difratogramas de raios-X de filmes de PVDF obtidos por solução em diferentes temperaturas de evaporação. Solvente: DMA.

em massa, de POMA-TSA (mostrado no quadro em destaque na Figura 5). Estes resultados são bastante interessantes, pois permitem que condutividade elétrica, em uma larga faixa, seja conferida para o PVDF com a adição de quantidades bem menores do que com cargas metálicas. Com isso, estes materiais possuem grande potencial em aplicações que requerem condutividade elétrica, como por exemplo, dispositivos eletrônicos, eliminação de cargas estáticas, proteção contra corrosão, entre outras.

Diferentemente dos nossos resultados, os primeiros estudos ${ }^{[13]}$ com blendas de PVDF/POMA mostraram um baixo valor de condutividade elétrica $\left(\approx 10^{-10} \mathrm{~S} / \mathrm{cm}\right)$ para alta quantidade de POMA $(20 \%)$. As discrepâncias podem ser atribuídas à utilização da POMA sintetizada em um ácido que não é o melhor meio reacional para a sua polimerização, assim como a não otimização nas condições de preparação das blendas. Desta forma, no nosso caso conseguimos obter condutividade de $\approx 10^{-10} \mathrm{~S} / \mathrm{cm}$ para conteúdo menor que $1 \%$ de POMA e condutividade de $\approx 10^{-3} \mathrm{~S} / \mathrm{cm}$ para $20 \%$ de POMA pela utilização de condições otimizadas mais adequadas para a preparação das blendas, determinadas neste estudo.

Para melhor entender o efeito das condições de preparação nas propriedades das blendas, realizouse uma caracterização morfológica e estrutural dos vários materiais obtidos, conforme descrito a seguir.

Sabe-se que o PVDF apresenta um polimorfismo com quatro fases semicristalinas $\alpha, \beta, \delta$ e $\gamma^{[14]}$. Destas quatro fases, a fase $\alpha$ (não polar) é a mais comum e a fase $\beta$ (polar) a mais importante por apresentar atividades piezo e piroelétrica mais elevadas. Estas conformações podem ser obtidas em condições adequadas e específicas de cristalização ${ }^{[14,15]}$. A temperatura de cristalização influencia diretamente na formação destas fases semicristalinas do $\mathrm{PVDF}^{[15]}$. Isto pode ser comprovado nos difratogramas apresentados na Figura 6 de filmes de PVDF obtidos a partir de solução com o solvente DMA para as temperaturas de $50,70,90,110,130$ e $150^{\circ} \mathrm{C}$. Analisando estes difratogramas, verifica-se que para temperaturas acima de $90^{\circ} \mathrm{C}$ a estrutura cristalina corresponde à da fase $\alpha$ indicada pela presença de picos característicos em $2 \theta$ igual a $26,5^{\circ}$ (plano cristalino 021 ), $19,9^{\circ}$ $(110), 18,3^{\circ}(020)$ e $17,6^{\circ}(100)^{[14]}$. Já para as temperaturas de 50 e $70^{\circ} \mathrm{C}$ a estrutura predominante é a da fase $\beta$ caracterizada pelo pico localizado em $20,5^{\circ}$ $[(100)+(200)]$.

$\mathrm{Na}$ Figura 7 pode-se observar que a presença de 25\% (em massa) de POMA dopada na blenda aparentemente não destrói a estrutura cristalina do PVDF, que continua apresentando os picos de difração de raios-X da fase $\beta$ e/ou fase $\alpha$, dependendo da temperatura de evaporação do solvente. Esta blenda apresenta um comportamento similar ao do PVDF, ou seja, aumento de fase $\alpha$ com o aumento da temperatura de evaporação. Este comportamento é, no entanto, menos evidenciado na blenda devido à presença de POMA, que apresenta vários picos de difração, sendo o mais intenso em torno de $2 \theta=7,0^{\circ}$, devido a regiões mais ordenadas ${ }^{[16]}$.

As micrografias das blendas de PVDF/POMATSA (75/25), obtidos a 50, 90 e $130^{\circ} \mathrm{C}$ são apresenta-

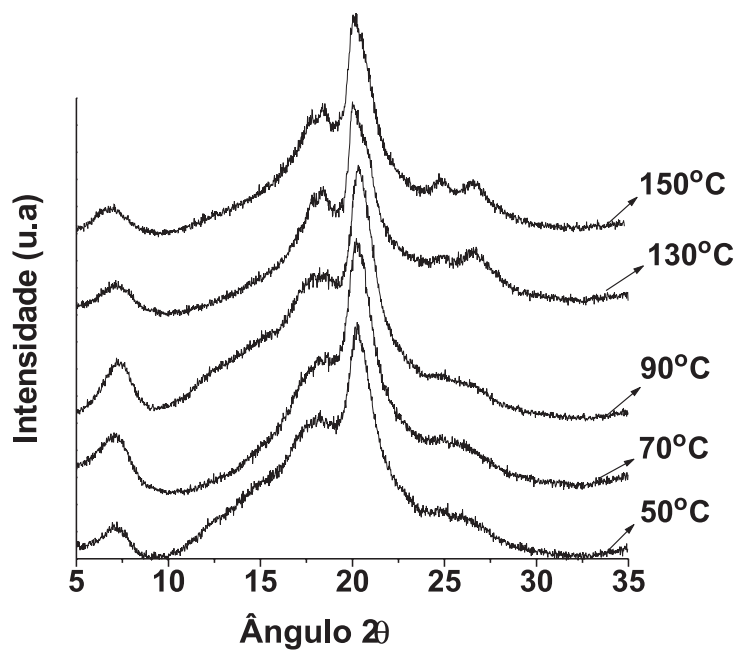

Figura 7. Difratogramas de raios-X de filmes das blendas de PVDF/ POMA (75/25)-TSA obtidos por solução (DMA) a diferentes temperaturas de evaporação. 


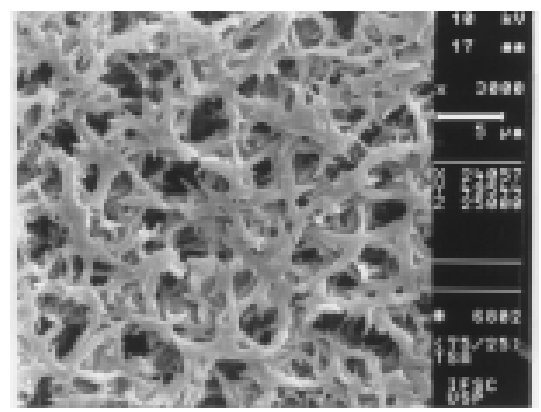

Figura 8a- Fotografia obtida por MEV do filme da blenda de PVDF/POMA (75/25) dopado com TSA e obtido a $50^{\circ} \mathrm{C}$. Solvente: DMA.

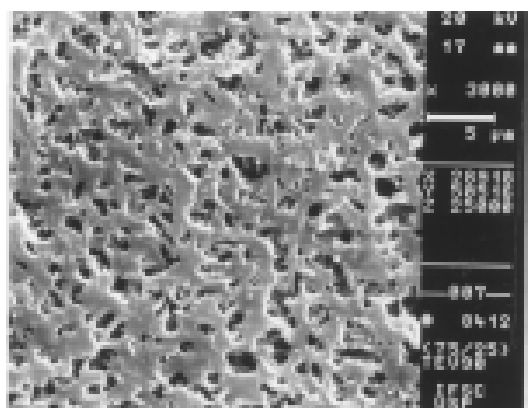

Figura 8b - Fotografia obtida por MEV do filme da blenda de PVDF/POMA (75/25) dopado com TSA e obtido a $90^{\circ} \mathrm{C}$. Solvente: DMA

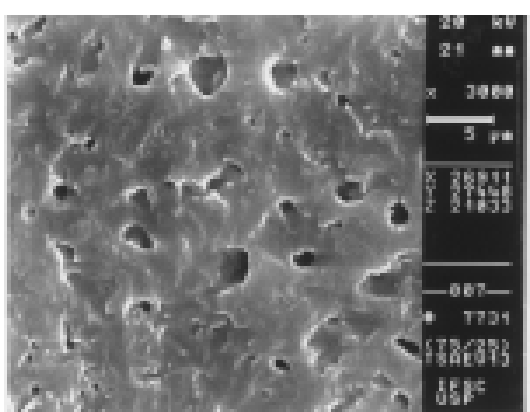

Figura 8c - Fotografia obtida por MEV do filme da blenda de PVDF/POMA (75/25) dopado com TSA e obtido a $130^{\circ} \mathrm{C}$. Solvente: DMA. das, respectivamente, nas Figuras 8 a, b e c. Nota-se que os filmes apresentam uma morfologia fibrilar característica do polímero condutor ${ }^{[16]}$. Acredita-se que tais fibrilas contribuem para a formação de caminhos condutores na matriz isolante do PVDF, que são responsáveis pela alta condutividade obtida para estes materiais. Para os filmes obtidos a 90 e $130^{\circ} \mathrm{C}$ a morfologia é mais compacta em relação ao filme obtido a $50^{\circ} \mathrm{C}$. Esta mudança morfológica deve contribuir para o decréscimo observado no valor da condutividade (Figura 3) discutido anteriormente, principalmente para o filme obtido a $130^{\circ} \mathrm{C}$, onde a morfologia fibrilar não é mais observada.

\section{Conclusões}

As condições de preparação de filmes de blendas de PVDF/POMA obtidos por solução influem decisivamente nas propriedades desses materiais. A condutividade elétrica e a qualidade (flexibilidade e homogeneidade) dos filmes produzidos dependem significativamente do solvente, do dopante e das condições de preparação da amostra. Os resultados de efeito da temperatura e do tempo de evaporação do solvente na condutividade elétrica das blendas de PVDF/POMA (75/25), dopada com TSA, indicaram que os filmes obtidos a $50^{\circ} \mathrm{C}$ tornam-se mais condutores e mais homogêneos que os filmes obtidos em temperaturas superiores, e que o tempo de evaporação tem pouca influência no valor da condutividade. A quantidade de dopante que resulta nos maiores valores de condutividade elétrica e melhor flexibilidade do filme é de $50 \%$, consistente com o número de nitrogênios imina presentes na cadeia polimérica. Filmes flexíveis e auto-sustentáveis da blenda de (PVDF/POMA)-TSA foram obtidos em condições otimizadas. Estes apresentam condutividade elétrica em uma larga faixa $\left(10^{-12}-10^{-2} \mathrm{~S} / \mathrm{cm}\right)$, onde para baixos teores de POMA-TSA ( $<2,5 \%$ em massa) já se atinge alto valor de condutividade $\left(10^{-7} \mathrm{~S} / \mathrm{cm}\right)$, não sendo definida uma composição mínima para percolação. Resultados de raios-X indicaram que a $50^{\circ} \mathrm{C}$ tanto o PVDF como a blenda se cristalizam predominantemente na fase $\beta$, indicando que para conteúdos de até $25 \%$ de POMA-TSA não há destruição da estrutura cristalina do PVDF.

\section{Agradecimentos}

Os autores agradecem à FAPESP, CAPES e CNPq pelo suporte financeiro.

\section{Referências Bibliográficas}

1. Macdiarmid, A.G. - Synth. Met., v.84, 27 (1997).

2. Genies, E.M.; Boyle, A.; Lapkowski, M.; Tsintavis, C. - Synth. Met., 36, 139 (1990).

3. Angelopoulus, M. Ray, A.; Macdiarmid, A.G.; Epstein, A.J. - Synth. Met., v.21, 21-30 (1987).

4. Cao, Y.; Smith, P.; Heeger, A.J. - Synth.Met., v.32, 263-281 (1989).

5. Fu, Y.; Weiss, R. A.- Synth. Met., v.84, 103 (1997).

6. Virtaen, E.; Laakso, J.; Ruohonen, H.; Vakiparta, K.; Jarvinen, H.; Jussila, M.; Passiniemi, P.; Osterholm, J.-E. - Synth. Met., v.84, 113 (1997).

7. Laska, J.; Zak, K.; Pron, A.- Synth. Met., v.84, 117 (1997).

8. Davies, S.J.; Ryan, T.G.; Wilde, C.J.; Beyer, G.Synth. Met., v.69, 209-210, (1995). 
9. Macinnes JR, D. “Contemporary Topics in Polymer Science", v.7, Edited by J.C. Salamone and J. Riffle, Plenum Press, New York (1992).

10. Yang, C.Y.; Cao, Y.; Smith, P.; Heeger, A.J. - Synth. Met., v.53, 293-301 (1993).

11. Mattoso, L.H.C. - Química Nova, v.19, 388-399 (1996).

12. Masters, J.G.; Sun, Y.; Macdiarmid, A.G.; Epstein, A.J. - Synth. Met., v.41-43, 715-718, (1991).

13. Mammone, R.J.; Wade JR, W.L.; Binder, M.- in: Proceedings of the 25th Intersociety Energy Conversion Engineering Conference, Nevada, 385-389 (August 1990).
14. Lovinger, A.J.- Developments in Crystalline Polymers - 1, D.C. Basset Ed., Apllied Science Publisher, Condon (1982).

15. Gregório Jr, R.; Cestari, M.- J. Polym. Sci. Part A: Polym. Phys., v.32, 859-870, (1994).

16. Malmonge, L.F. "Preparação e caracterização de blendas de poli(fluoreto de vinilideno) com polianilinas", Tese de Doutorado, Universidade de São Paulo, São Carlos, (1996).

Recebido: 01/12/97

Aprovado: 05/03/98 